\title{
EFEITO DO ESTRESSE HÍDRICO E SALINO NO VIGOR E GERMINAÇÃO DE SEMENTES DE FEIJÃO-VAGEM (Phaseolus vulgaris L.)
}

\author{
Guilherme Renato Gomes ${ }^{1}$, Luiz Henrique Campos de Almeida ${ }^{2}$, Lúcia Sadayo Assari \\ Takahashi $^{3}$
}

\footnotetext{
${ }^{1}$ Mestrando na Universidade Estadual de Londrina (PR).

${ }^{2}$ Doutorando na Universidade Estadual de Londrina (PR).

${ }^{3}$ Professora Doutora do Departamento de Agronomia na Universidade Estadual de Londrina (PR).
}

RESUMO: O experimento foi conduzido no laboratório de Tecnologia e Produção de Sementes da Universidade Estadual de Londrina-PR. Objetivou-se avaliar o efeito do estresse hídrico e salino no vigor e germinação de sementes de feijão-vagem. Os gradientes de potenciais osmóticos foram obtidos por meio de diluições de solução salina estoque de $\mathrm{NaCl} \mathrm{PA}$, de potencial $-2,1 \mathrm{MPa}$, preparada previamente. Os tratamentos corresponderam aos seguintes potenciais osmóticos: $0,0:-0,4 ;-0,8 ;-1,2 ;-1,6 ;-2,0 \mathrm{MPa}$. A semeadura foi realizada em rolos de papel tipo germitest, constituídos de três folhas cada, umedecidas com volume de solução equivalente a duas vezes e meia a sua massa seca e, posteriormente, mantidos em germinador a temperatura constante de $25^{\circ} \mathrm{C}$. Os efeitos do estresse hídrico e salino foram avaliados pelos seguintes parâmetros: primeira contagem de germinação (PCG), porcentagem de germinação (PG), comprimento do sistema radicular (CSR), comprimento da parte aérea (CPA), comprimento total (CT), massa seca do sistema radicular (MSSR), massa seca da parte aérea (MSPA) e massa seca total (MST). As variáveis PCG e PG não foram influenciadas pelos estresses hídrico e salino, apresentando o mesmo comportamento da testemunha. Para as variáveis CSR, CPA e CT, o potencial osmótico de -1,2 MPa mostrou-se como o limiar de salinidade para o desenvolvimento da parte aérea. Em relação ao sistema radicular, tal limiar foi observado a -1,6 MPa. Quanto à MSSR, MSPA e MST, a partir do potencial -0,4 MPa constatou-se redução no acúmulo de massa seca total das plântulas.

Palavras-chave: Germinação. Phaseolus vulgaris. Potencial osmótico.

\section{EFFECT OF WATER AND SALT STRESS IN FORCE AND SEED GERMINATION OF SNAP BEAN (Phaseolus vulgaris $\mathbf{L}$.)}

\begin{abstract}
The experiment was conducted in the laboratory of Seed Production Technology of the State University of Londrina, Paraná state. Aimed to evaluate the effect of water and salt stress on force and seed germination of snap bean. The gradients of osmotic potential were obtained by dilutions of the $\mathrm{NaCl}$ PA stock solution, to potential of 2.1 MPa, previously prepared. The treatments corresponded to the following osmotic potential: $-0,4 ;-0,8 ;-1,2 ;-1,6 ;-2,0 \mathrm{MPa}$ and witness. The seeding on was done in the paper rolls germitest type, consisting of three sheets each, moistened with solution volume equivalent to two and a half times its dry mass and subsequently kept in germinator at a
\end{abstract}

Cultura Agronômica, Ilha Solteira, v.24, n.1, p.83-92, 2015 
constant temperature of $25^{\circ} \mathrm{C}$. The effects of water and salinity stress were evaluated by the following parameters: first count of germination (PCG), germination percentage (PG), length of the root system (CSR), shoot length (CPA), total length (TL), dry root weight (RDW), shoot dry mass (MSPA) and total dry mass (MST). The PCG and PG variables were not affected by water and salt stress, exhibiting the same behavior of the witness. For CSR, CPA and CT variables, the osmotic potential of -1.2 MPa showed up as the threshold salinity for the development of shoots. In relation to the root, such a threshold was observed at -1.6. As for the MSSR, MSPA and MST, from -0.4 MPa potential was found reduction in the accumulation of total dry weight of seedlings.

Key words: Germination. Phaseolus vulgaris. Osmotic potential.

\section{INTRODUÇÃO}

O feijão-vagem pertence à mesma família e espécie botânica do feijão comum (Phaseolus vulgaris L.), sendo de grande importância econômica e social no Brasil, especialmente para a agricultura familiar (FILGUEIRA, 2000). Difere-se do feijão comum, pois suas vagens são colhidas ainda imaturas e, nesse estádio, podem ser utilizadas de diversas formas na alimentação, tanto na forma industrializada quanto in natura (HAESBAERT et al., 2011).

Considerada uma espécie de ampla adaptação climática, o feijão-vagem nem sempre dispõe de solos cultiváveis em condições ideais de semeadura, pois, em sua grande maioria, apresentam deficiência hídrica e salina (MACHADO NETO et al., 2006; COELHO et al., 2010).

A absorção de água pelas plantas é diretamente relacionada à salinidade, constituindo fator preponderante da baixa disponibilidade hídrica em solos salinos, principalmente em áreas irrigadas (D’ALMEIDA et al., 2005). A presença de sais promove aumento das forças de retenção da água no solo, dificultando as respostas fisiológicas e metabólicas da planta, prejudicando seu desenvolvimento desde a germinação, o que pode acarretar em redução na produtividade e, em casos mais severos, pode levar a morte da planta (FARIAS, 2008; DIAS; BLANCO, 2010).

Nas sementes, a restrição hídrica e os efeitos causados pela salinidade podem atrasar a germinação, em etapas envolvendo divisão e alongamento celular, mobilização de reservas, e, por consequiência, o estabelecimento da plântula e o desenvolvimento de diversas espécies em diferentes regiões (MARCOS FILHO, 2005; NOGUEIRA et al., 2005; LIMA et al., 2005).

Assim, torna-se necessário definir as condições de estresse menos deletérias aos processos iniciais de germinação e estabelecimento das plântulas. Desta forma, objetivou-se avaliar o efeito do estresse hídrico e salino no vigor e germinação de sementes de feijãovagem.

Cultura Agronômica, Ilha Solteira, v.24, n.1, p.83-92, 2015 


\section{MATERIAL E MÉTODOS}

O trabalho foi conduzido no laboratório de Tecnologia e Produção de Sementes da Universidade Estadual de Londrina (UEL), Londrina-PR, em abril de 2014. Foram utilizadas sementes de feijão-vagem de crescimento determinado, denominadas macarrão rasteiro, da empresa de sementes Top Seed®.

Para a obtenção dos gradientes de potenciais osmóticos, foi previamente preparada solução salina estoque de $\mathrm{NaCl} \mathrm{PA}$, de potencial osmótico correspondente a $-2,1 \mathrm{MPa}$ e, posteriormente, diluída aos gradientes de potenciais osmóticos desejados, por meio da equação de Van' t Hoff citada por Pimenta (2004): $\Psi_{\mathrm{S}}=-\mathrm{RTCs}$, onde $\Psi_{\mathrm{S}}=$ potencial osmótico $(\mathrm{MPa}), \mathrm{R}=$ constante dos gases $\left(0,8093 \mathrm{MPa} \mathrm{mol}^{-1} \cdot \mathrm{k}^{-1}\right), \mathrm{Cs}=$ concentração (mol. $\left.\mathrm{L}^{-1}\right)$, sendo que, para solutos iônicos que se dissociam em duas ou mais partículas, Cs deve ser multiplicado pelo número de partículas dissociadas, no caso do $\mathrm{NaCl}$ este valor é dois, $\mathrm{T}=$ temperatura absoluta $(\mathrm{K})$. Os gradientes de potenciais osmóticos utilizados corresponderam a: - 0,$4 ;-0,8 ;-1,2,-1,6$ e -2,0 MPa de soluções de $\mathrm{NaCl}$ e testemunha.

A semeadura foi realizada em rolos de papel tipo germitest, constituídos de três folhas cada, umedecidas com volume de solução equivalente a duas vezes e meia a sua massa seca e, posteriormente, mantidos em germinador a temperatura constante de $25^{\circ} \mathrm{C}$.

As características avaliadas foram: primeira contagem de germinação (PCG), porcentagem de germinação (PG), comprimento do sistema radicular (CSR), comprimento da parte aérea (CPA), comprimento total (CT), mensurados com o auxílio de régua milimetrada, massa seca do sistema radicular (MSSR), massa seca da parte aérea (MSPA) e massa seca total (MST). Para obtenção das massas secas, as amostras das plântulas foram acondicionadas em sacos de papel e colocadas em estufa com circulação forçada de ar com temperatura de $50^{\circ} \mathrm{C}$, até atingirem massa constante.

O delineamento experimental foi inteiramente casualizado com quatro repetições de 50 sementes por rolo. Os dados foram submetidos à análise de regressão, para ajuste de modelos adequados. A análise de variância foi conduzida aplicando-se o teste F, com médias comparadas pelo teste Tukey a 5\%, com auxílio do programa estatístico Sisvar@.

As características porcentagem de germinação (PG), comprimento do sistema radicular (CSR), comprimento de parte aérea (CPA) e massas secas do sistema radicular, parte aérea e total (MSSR, MSPA e MST) foram apresentadas em tabelas, pois não se ajustaram a nenhum modelo de regressão de forma satisfatória.

\section{RESULTADOS E DISCUSSÃO}

Quanto a PCG pode-se observar que a redução gradativa do potencial osmótico pela variação da concentração de $\mathrm{NaCl}$, ou seja, a redução da disponibilidade de água às sementes não alterou o desempenho germinativo da espécie, apresentando comportamento semelhante às sementes não submetidas ao estresse (Figura 1).

Cultura Agronômica, Ilha Solteira, v.24, n.1, p.83-92, 2015 


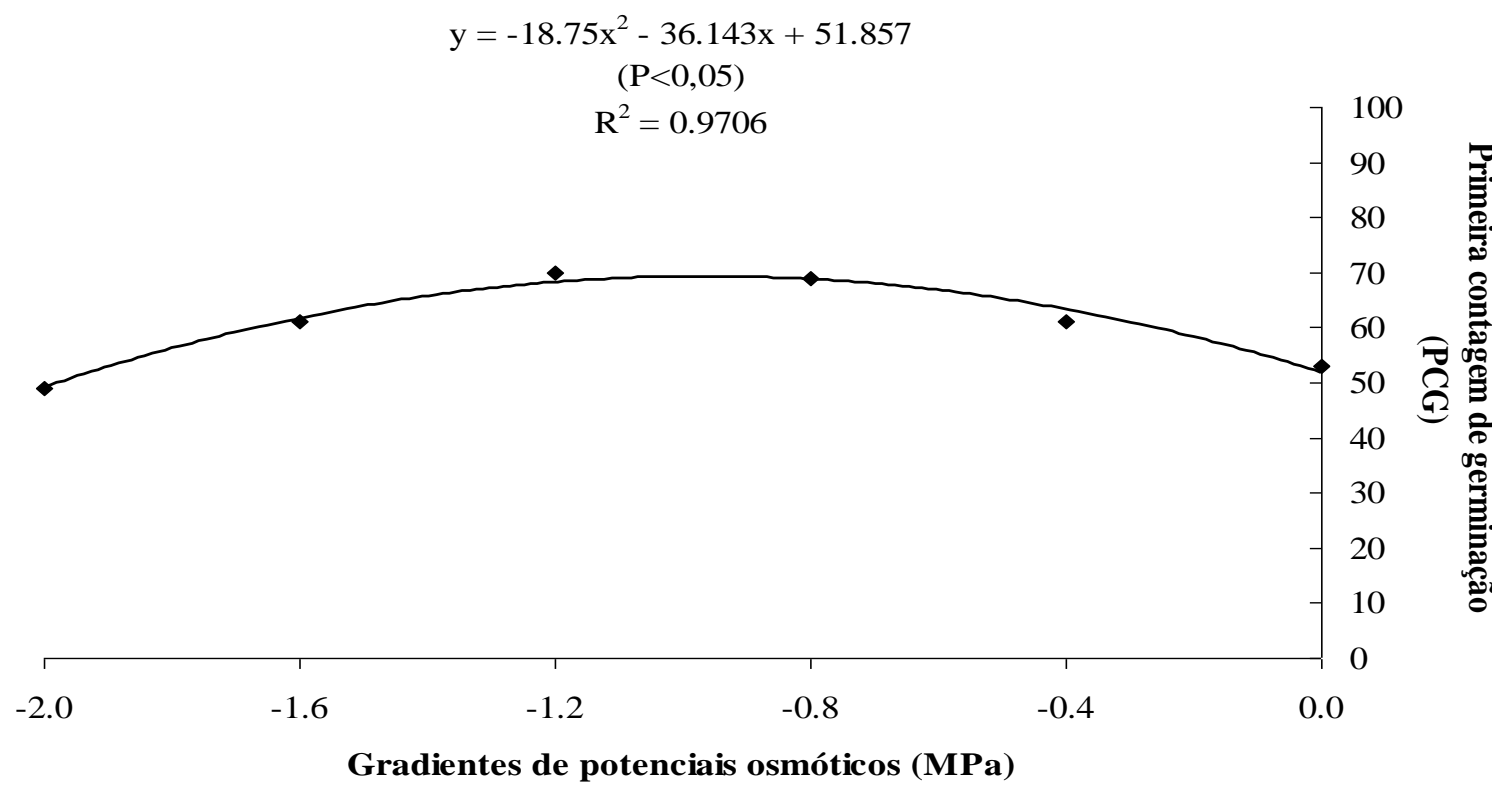

Figura 1. Modelo de regressão para primeira contagem de germinação (PCG) de sementes de feijão-vagem submetidas a diferentes gradientes de potenciais osmóticos de soluções de $\mathrm{NaCl}$. Londrina, 2014.

Também nota-se que na PCG, variável esta que mostra o vigor das sementes, que os valores concentraram-se em torno de $60 \%$. No entanto, este comportamento foi verificado tanto na testemunha quanto nos demais tratamentos, indicando que, nas condições deste trabalho, o estresse salino não interferiu na PCG e os valores médios observados para a variável podem ser explicados por fatores inerentes as sementes, tanto externos como condições de colheita e tempo de armazenamento até a comercialização, quanto internos, relacionados a fatores intrínsecos à qualidade fisiológica das sementes, como vigor e germinação reduzidos.

Tabela 1. Porcentagem de germinação (PG) de sementes de feijão-vagem submetidas a diferentes gradientes de potenciais osmóticos de soluções de $\mathrm{NaCl}$. Londrina. 2014.

\begin{tabular}{c|c}
\hline Gradientes de potenciais osmóticos (-MPa) & $\begin{array}{c}\text { Germinação } \\
(\%)\end{array}$ \\
\hline 0,0 & $83 \mathrm{a}$ \\
0,4 & $84 \mathrm{a}$ \\
0,8 & $94 \mathrm{a}$ \\
1,2 & $88 \mathrm{a}$ \\
1,6 & $73 \mathrm{a}$ \\
2,0 & $83 \mathrm{a}$ \\
\hline CV (\%) & $\mathbf{1 5 , 4 9}$ \\
\hline Média geral & $\mathbf{8 4 , 1 7}$ \\
\hline
\end{tabular}

*Médias seguidas pela mesma letra minúscula, na coluna, não diferem entre si pelo teste Tukey a 5\% de probabilidade.

Quanto à porcentagem de germinação (PG), seu desempenho foi semelhante à PCG, indicando que a redução do gradiente de potencial osmótico não alterou a resposta das sementes submetidas ao estresse em relação às sementes não submetidas a esta condição Cultura Agronômica, Ilha Solteira, v.24, n.1, p.83-92, 2015 
(Tabela 1). Desta forma, a germinação das sementes não foi afetada com o incremento da salinidade até -2,0 MPa.

Contrariamente ao observado neste estudo, Moraes et al. (2005), trabalhando com estresse salino por $\mathrm{NaCl}$, em sementes de feijão comum (Phaseolus vulgaris L.) observaram, quanto a primeira contagem de germinação, que a formação de plântulas normais manteve-se igual até potencias de $-0,2 \mathrm{MPa}$, com redução drástica a partir desse valor. Estes mesmos autores, também verificaram resposta inversa ao comportamento observado neste trabalho, quanto à germinação das sementes, na qual, a partir de $-0,3 \mathrm{MPa} a$ germinação foi insignificante.

Os resultados obtidos por estes autores corroboram com Coelho et al. (2010) em sementes de feijão comum e com Santos et al. (1992), Braccini et al. (1996) e Moraes \& Menezes (2003) que relataram redução no vigor e na germinação de sementes de soja, à medida que o potencial osmótico das soluções de $\mathrm{NaCl}$ tornou-se mais negativo, sendo que, a partir -0,8 MPa não ocorreu a germinação de sementes. Pinheiro et al. (2013), em estudo realizado com estresse salino induzido por $\mathrm{NaCl}$ em feijão guandu (Cajanus cajan), obtiveram resultados semelhantes aos autores acima, pois verificaram decréscimo no vigor e na germinação das sementes a partir do potencial de -0,9 MPa. Jeller \& Perez (2001), trabalhando com Senna spectabilis, também observaram redução na germinação quando o potencial das soluções de $\mathrm{NaCl}$ tornou-se mais negativo.

Para Van Der Moezel \& Bell (1987), o NaCl afeta a germinação pelo efeito osmótico e/ou iônico, dificultando a absorção de água ou facilitando a penetração de íons nas células. Quanto aos decréscimos no vigor bservados pelos autores, Bruni \& Leopold (1992) sugerem que tal comportamento é decorrente da deficiência hídrica, acarretando perda progressiva da turgescência protoplasmática e aumento na concentração de solutos, causando distúrbio em funções celulares e danos no sistema de membranas.

Tabela 2. Comprimento do sistema radicular (CSR), da parte aérea (CPA) e total (CT) de plântulas de feijão-vagem submetidas a diferentes gradientes de potenciais osmóticos de soluções de $\mathrm{NaCl}$. Londrina, 2014.

\begin{tabular}{c|ccc}
\hline Gradientes de Potenciais Osmóticos & \multicolumn{3}{|c}{ Comprimento (cm) } \\
\cline { 2 - 4 } (-MPa) & Sistema Radicular & Parte Aérea & Total \\
\hline 0,0 & $8,95 \mathrm{ab}$ & $5,69 \mathrm{abc}$ & $14,64 \mathrm{~b}$ \\
0,4 & $8,13 \mathrm{ab}$ & $6,33 \mathrm{a}$ & $14,46 \mathrm{c}$ \\
0,8 & $8,39 \mathrm{ab}$ & $5,14 \mathrm{bc}$ & $13,53 \mathrm{c}$ \\
1,2 & $9,98 \mathrm{a}$ & $6,08 \mathrm{ab}$ & $16,06 \mathrm{a}$ \\
1,6 & $8,95 \mathrm{ab}$ & $5,30 \mathrm{bc}$ & $14,25 \mathrm{c}$ \\
2,0 & $7,49 \mathrm{~b}$ & $4,60 \mathrm{c}$ & $12,09 \mathrm{~d}$ \\
\hline CV $(\%)$ & $\mathbf{9 , 6 3}$ & $\mathbf{8 , 2 9}$ & $\mathbf{9 , 2 6}$ \\
\hline Média Geral & $\mathbf{8 , 6 5}$ & $\mathbf{5 , 4 9}$ & $\mathbf{1 4 , 1 7}$ \\
\hline
\end{tabular}

*Médias seguidas pela mesma letra minúscula, na coluna, não diferem entre si pelo teste Tukey a $5 \%$ de probabilidade.

Quanto ao comprimento do sistema radicular, nota-se, na Tabela 2, que não houve diferença entre os tratamentos até o potencial -1,6 Mpa, e, consequentemente, apresentaram

Cultura Agronômica, Ilha Solteira, v.24, n.1, p.83-92, 2015 
as melhores médias para a variável. Essa diferença só foi constatada no potencial mais negativo entre os tratamentos, de -2,0 MPa, observando-se redução no comprimento da raiz.

Para parte aérea, os potenciais -0,4 e -1,2 MPa não diferiram entre si e perante a testemunha e, desta forma, apresentaram os melhores desempenhos para o comprimento. No entanto, o potencial que demonstrou melhor desempenho geral, ou seja, que menos influenciou para a redução do desenvolvimento das raízes foi -1,2 $\mathrm{MPa}$, possivelmente, o limiar de salinidade para o desenvolvimento da espécie.

De forma contrária ao observado neste trabalho, Gama et al. (2009), em experimento conduzido com estresse salino em feijão comum, verificaram redução no comprimento de raiz e parte aérea, por meio da influência negativa da salinidade, mostrando que, apesar de serem da mesma espécie, o feijão-vagem mostrou maior tolerância a este estresse, provavelmente em decorrência de adaptações da espécie.

Aliado a isso, a variação nas respostas das plantas a maiores ou menores concentrações de sais no solo, decorre da característica de cada tipo de planta, e seus efeitos no rendimento final da cultura poderão ser influenciados por outros fatores como natureza osmótica, tóxica ou nutricional (VIANA et al., 2004), corroborando com este trabalho quanto ao comportamento observado para os comprimentos dos sistema radicular e parte aérea no potencial $-1,2 \mathrm{MPa}$.

Em relação ao crescimento das plantas, mensurados a partir do acúmulo de massa seca, observa-se na Tabela 3 que, para o sistema radicular, todos os tratamentos foram inferiores a média observada na testemunha, indicando que a salinidade interferiu negativamente na absorção de nutrientes e, consequentemente, no acúmulo de massa.

Tabela 3. Massa seca do sistema radicular (MSSR), da parte aérea (MSPA) e total (MST) de plântulas de feijão-vagem submetidas a diferentes gradientes de potenciais osmóticos de soluções de $\mathrm{NaCl}$. Londrina, 2014.

\begin{tabular}{c|ccc}
\hline $\begin{array}{c}\text { Gradientes de Potenciais Osmóticos } \\
\text { (-MPa) }\end{array}$ & \multicolumn{3}{|c}{ Massa Seca (g) } \\
\cline { 2 - 4 } & Sistema Radicular & Parte Aérea & Total \\
\hline 0,0 & $0,34 \mathrm{a}$ & $1,38 \mathrm{a}$ & $1,72 \mathrm{a}$ \\
0,4 & $0,13 \mathrm{e}$ & $1,44 \mathrm{a}$ & $1,57 \mathrm{~b}$ \\
0,8 & $0,28 \mathrm{c}$ & $1,16 \mathrm{c}$ & $1,44 \mathrm{c}$ \\
1,2 & $0,15 \mathrm{~d}$ & $1,42 \mathrm{a}$ & $1,57 \mathrm{~b}$ \\
1,6 & $0,28 \mathrm{c}$ & $1,29 \mathrm{~b}$ & $1,57 \mathrm{~b}$ \\
2,0 & $0,29 \mathrm{~b}$ & $1,08 \mathrm{~d}$ & $1,37 \mathrm{c}$ \\
\hline CV $(\%)$ & $\mathbf{3 4 , 5 1}$ & $\mathbf{1 1 , 3 7}$ & $\mathbf{7 , 9 0}$ \\
\hline Média Geral & $\mathbf{0 , 2 5}$ & $\mathbf{1 , 3 0}$ & $\mathbf{1 , 5 4}$ \\
\hline
\end{tabular}

*Médias seguidas pela mesma letra minúscula, na coluna, não diferem entre si pelo teste Tukey a 5\% de probabilidade.

Para a parte aérea, os potenciais -0,4 e -1,2 MPa não diferiram entre si e perante a testemunha, apresentando as melhores médias para o acúmulo de massa. No entanto, o melhor desempenho geral ocorreu na ausência de estresse hídrico e salino, ou seja, a testemunha apresentou a melhor média de acúmulo de massa seca, sugerindo que esta variável, para o feijão-vagem, está diretamente relacionada à presença de sais na solução do 
solo, evidenciando sua influência negativa no comportamento da variável.

Ao contrário do observado neste trabalho, Lopes \& Macedo (2008), em trabalho realizado com sementes de couve chinesa (Brassica pekinensis), observaram que, em sementes com $16 \%$ de umidade, não houve interferência no acúmulo de massa seca e que, em sementes com $8 \%$ de umidade, houve aumento de massa no potencial $-0,8 \mathrm{MPa}$ de solução de $\mathrm{NaCl}$.

Este comportamento sugere maior tolerância da espécie com relação à salinidade. Queiroz et al. (2013), em estudo sobre tolerância à salinidade com a cultura da berinjela, também constataram ausência de influência dos sais sobre o crescimento e desenvolvimento das plantas. Corroborando com estes autores, Coelho et al. (2010), verificaram para feijão comum que, as massas secas de raiz, parte aérea e total, reduziram na presença de diferentes níveis de potenciais de $\mathrm{NaCl}$, sendo detectada tal ocorrência a partir de -0,1 Mpa. Desempenhos corroborados por Braccini et al. (1996), Moraes \& Menezes (2003), Machado Neto et al. (2004), Costa et al. (2004), Machado et al. (2006) e Custódio et al. (2009). Em trabalho realizado com feijão guandu (Cajanus cajan), Freitas et al. (2003) também obtiveram resultados semelhantes, verificando redução no acúmulo de massa da parte aérea e, consequentemente, no acúmulo total de massa seca das plântulas.

\section{CONCLUSÕES}

Não houve influência do estresse hídrico e salino no vigor e na germinação das sementes de feijão-vagem.

O potencial osmótico -1,2 $\mathrm{MPa}$ mostrou-se como o limiar de salinidade para o desenvolvimento, tanto em comprimento, do sistema radicular como da parte aérea.

O limiar de salinidade para o sistema radicular ocorreu a -1,6 $\mathrm{MPa}$.

Houve redução no acúmulo de massa seca total das plântulas de feijão-vagem a partir do potencial -0,4 MPa.

\section{REFERÊNCIAS BIBLIOGRÁFICAS}

BRACCINI, A. L.; RUIZ, H. A.; BRACCINI, M. C. L.; REIS, M. S. Germinação e vigor de sementes de soja sob estresse hídrico induzido por soluções de cloreto de sódio, manitol e polietilenoglicol. Revista Brasileira de Sementes, Viçosa, v. 18, n. 1, p.10-16, 1996.

BRUNI, F. B.; LEOPOLD, A. C. Cytoplasmic glass formation in maize embryos. Seed Science Research, New York, v. 2, n. 4, p.251-253, 1992.

COElHO, D. L. M; AGOSTINI, E. A. T; GUABERTO, L. M; NETO, N. B. M; CUSTÓDIO, C. C. Estresse hídrico com diferentes osmóticos em sementes de feijão e expressão diferencial de proteínas durante a germinação. Acta Scientiarum Agronomy, Maringá, v. 32, n. 3, p.491-499, 2010.

Cultura Agronômica, Ilha Solteira, v.24, n.1, p.83-92, 2015 
COSTA, P. R.; CUSTÓDIO, C. C.; MACHADO NETO, N. B.; MARUBAYASHI, O. M. Estresse hídrico induzido por manitol em sementes de soja de diferentes tamanhos. Revista Brasileira de Sementes, Presidente Prudente, v. 26, n. 1, p.105-113, 2004.

CUSTÓDIO, C. C.; SALOMÃO, G. R.; MACHADO NETO, N. B. Estresse hídrico na germinação e vigor de sementes de feijão submetidas a diferentes soluções osmóticas. Revista Ciência Agronômica, Presidente Prudente, v. 40, n. 4, p.617-623, 2009.

D’AlMEIDA, D. M. B. A.; ANDRADE, E. M.; MEIRELES, A. C. M.; NESS, R. L. L. Importância relativa dos íons na salinidade de um Cambissolo na Chapada do Apodi, Ceará. Engenharia Agrícola, Jaboticabal, v. 25, n. 3, p.615-621, 2005.

DIAS, N. S.; BLANCO, F. F. Efeitos dos sais no solo e na planta. In: GHEYI, H. R.; DIAS, N. S.; LACERDA, C. F (Ed). Manejo da salinidade na agricultura: estudos básicos e aplicados. Fortaleza: INCTSal, 2010. cap 9, p. 129-141.

FARIAS, S. G. G. Estresse osmótico na germinação, crescimento e nutrição mineral de glicirídia (Gliricidia sepium (Jacq.). 2008. 61 f. Dissertação (Mestrado em Agronomia) Universidade Federal de Campina Grande, Campina Grande, 2008.

FILGUEIRA, F. A. R. Novo manual de olericultura: agrotecnologia moderna na produção de hortaliças. Viçosa: UFV, 2000. 421 p.

FREITAS, A. D. S.; MEDEIROS, P. J. C.; SANTOS, C. E. R. S.; STANFORD, N. P. Fixação do $\mathrm{N}_{2}$ e desenvolvimento do Guandu inoculado com rizóbio em um cambissolo salinizado do Semi-árido. Agropecuária Técnica, Areia, v. 24, n. 2, p.87-95, 2003.

GAMA, P. B. S.; TANAKA, K.; ENEJI, A. E.; ELTAYEB, A. E.; SIDDIG, K. E. Salrinduced stress effect on biomass, photosynthetic rate, and reactive oxygen speciesscavenging enzyme accumulation in common bean. Journal of Plant Nutrition, Japan, v. 32, n. 5, p.837-854, 2009.

HAESBAERT, F. M; SANTOS, D; LÚCIO, A. D. C; BENZ, V; ANTONELLO, B. I; RIBEIRO, A. L. P. Tamanho de amostra para experimentos com feijão-de-vagem em diferentes ambientes. Ciência Rural, Santa Maria, v. 41, n. 1, p. 38-44, 2011.

JELLER, H.; PEREZ, S. C. J. G .A. Efeitos dos estresses hidrico e salino e da ação de giberelina em sementes de Senna spectabilis. Ciência Florestal, Santa Maria, v. 11, n. 1, p.93-104, 2001.

LIMA, M. G. S.; LOPES, N. F.; MORAES, D. M.; ABREU, C. M. Qualidade fisiológica de sementes de arroz submetidas a estresse salino. Revista Brasileira de Sementes, Pelotas, v. 27, n. 1, p.54-61, 2005.

Cultura Agronômica, Ilha Solteira, v.24, n.1, p.83-92, 2015 
LOPES, J. C.; MACEDO, C. M. P. Germinação de sementes de couve chinesa sob influência do teor de água, substrato e estresse salino. Revista Brasileira de Sementes, Porto Alegre, v. 30, n. 3, p.79-85, 2008.

MACHADO NETO, N. B.; SATURNINO, S. M.; BOMFIM, D. C.; CUSTÓDIO, C. C. Water stress induced by mannitol and sodium chloride in soybean cultivars. Brazilian Archives of Biology and Technology, Presidente Prudente, v. 47, n. 4, p.521-529, 2004.

MACHADO NETO, N. B.; CUSTÓDIO, C. C.; COSTA, P. R.; DONÁ, F. L. Deficiência hídrica induzida por diferentes agentes osmóticos na germinação e vigor de sementes de feijão. Revista Brasileira de Sementes, Presidente Prudente, v. 28, n. 1, p.142-148, 2006.

MARCOS FILHO, J. Fisiologia de sementes de plantas cultivadas. Piracicaba: FEALQ, 2005. $495 \mathrm{p}$.

MORAES, G. A. F.; MENEZES, N. L. Desempenho de sementes de soja sob condições diferentes de potencial osmótico. Ciência Rural, Santa Maria, v. 33, n. 2, p.219-226, 2003.

MORAES, G. A. F.; MENEZES, N. L.; PASQUALLI, L. L. Comportamento de sementes de feijão sob diferentes potenciais osmóticos. Ciência Rural, Santa Maria, v.35, n. 4, p.776780, 2005.

NOGUEIRA, R. J. M. C.; MORAES, J. A. P. V.; BURITY, H. A. Alterações na resistência à difusão de vapor das folhas e relações hídricas em aceroleiras submetidas a déficit de água. Revista Brasileira de Fisiologia Vegetal, Paudalho, v. 13, n. 1, p.75-87, 2005.

PINHEIRO, G. G.; ZANOTTI, R. F.; PAIVA, C. E. C.; LOPES, J. C.; GAI, Z. T. Efeito do estresse salino em sementes e plântulas de feijão guandu. Enciclopédia Biosfera, Goiânia, v. 9, n. 16, p. 901-912, 2013.

PIMENTA, J. A. Relações Hídricas. In: KERBAUY, G. B. (ed.). Fisiologia vegetal. Rio de Janeiro: Guanabara Koogan, 2004. cap. 1, p. 1-39.

QUEIROZ, I. S. R.; LEITÃO, A. R. F.; FERREIRA, L. L.; DIAS, N. S.; COSME, C. R.; MOTA, A. F. Tolerância da berinjela à salinidade cultivada em substrato de fibra de coco. Revista Agropecuária Científica no Semiárido, Mossoró, v. 9, n. 2, p.15-20, 2013.

SANTOS, V. L. M.; CALIL, A. C.; RUIZ, H. A.; ALVARENGA, E. M.; SANTOS, C. M. Efeito do estresse salino e hídrico na germinação e vigor de sementes de soja. Revista Brasileira de Sementes, v. 14, n. 2, p. 189-194, 1992.

Cultura Agronômica, Ilha Solteira, v.24, n.1, p.83-92, 2015 
VAN DER MOEZEL, P.G.; BELL, D. T. The effect of salinity on the germination of some Western Australian Eucalyptus and Melaleuca species. Seed Science \& Technology, Zürich, v. 15, n. 1, p.239-246, 1987.

VIANA, S. B. A.; FERNANDES, P. D.; GHEYI, H. R.; SOARES, F. A. L.; CARNEIRO, P. T. Índices morfofisiológicos e de produção de alface sob estresse salino. Revista Brasileira de Engenharia Agrícola e Ambiental, Campina Grande, v. 8, n. 1, p.23-30, 2004. 